\title{
Autonomous Medication Management (GAM): new perspectives on well-being, quality of life and psychiatric medication
}

\author{
Gestão Autônoma da Medicação (GAM): novas perspectivas \\ sobre bem-estar, qualidade de vida e medicação psiquiátrica
}

Lourdes Rodriguez del Barrio ${ }^{1}$

Céline Cyr ${ }^{1}$

Lisa Benisty ${ }^{1}$

Pierrette Richard ${ }^{1}$

${ }^{1}$ School of Social Work, University of Montreal. 2900 Blv ÉdouardMontpetit. Montréal QC H3T 1J4 Canada. lourdes.rodriguez.del.barrio@ umontreal.ca

\begin{abstract}
Autonomous Medication Management (GAM) is an innovative approach developed in partnership with medication users. It takes their subjective experience into account and strives to place the individual at the center of pharmacological treatment in psychiatry with a view to improving well-being and quality of life. It creates spaces of open dialogue on the issue of medication amongst users, physicians and their family and friends. This article is derived from a research study and presents the principles, practices and main impacts of GAM on how people relate to their medications and the physicians who prescribe them. The major positive effects were the users' clearer understanding of their experience of taking psychiatric medication and their rights, the reduction or elimination of sudden and unsupervised treatment interruptions and the users' sense of having more control over their treatment. It includes inner experience and life, an improved relationship with professionals and space for negotiation with the physician and, lastly, changes to prescriptions that significantly improved well-being and recovery. The distinguishing features of GAM are described and compared with other approaches, giving a voice to people who take medication.
\end{abstract}

Key words GAM, Mental health, Psychiatric medication, Qualitative research, Communitybased practices, Empowerment
Resumo A Gestão Autônoma da Medicação (GAM) é uma abordagem inovadora desenvolvida em parceria com usuários que fazem uso de medicação, considerando sua experiência subjetiva, se esforçando para colocar a pessoa no centro do tratamento farmacológico psiquiátrico, visando uma melhora no bem-estar e na qualidade de vida, criando oportunidades de expressão, diálogo e apoio entre as pessoas, os profissionais e seus próximos. Este artigo, resulta de uma pesquisa que apresenta os princípios, as práticas e os principais impactos da GAM no modo como as pessoas se relacionam com seus medicamentos e com os médicos que as prescrevem. Entre os principais efeitos observados, encontramos uma melhor compreensão da experiência, de seus direitos e do tratamento farmacológico; uma redução, ou eliminação das interrupções súbitas de tratamento e sem acompanhamento; uma percepção de maior controle sobre seu tratamento, sua experiência interior e sua vida; uma melhora no relacionamento entre profissionais com espaço para negociação; e mudanças nas prescrições, o que mostrou grande impacto no bem-estar, qualidade de vida na comunidade e restabelecimento (recovery). Características importantes da GAM são também identificadas em outras abordagens, dando voz às pessoas que utilizam medicação.

Palavras-chave Saúde mental, Medicação psiquiátrica, Pesquisa qualitativa, Práticas comunitárias, Empowerment 


\section{Contribution and limits of pharmacological treatments regarding recovery and wellness}

Mental health problems affect persons in their entirety. All aspects of their personal and social lives are disrupted: work, relationships, standard of living and physical health. Medication eases some symptoms but is rarely sufficient by itself to ensure a rewarding life in the community.

It is known that between one-quarter and one-half of all individuals considered schizophrenic do not obtain the desired results from neuroleptics despite taking them regularly ${ }^{1}$. The introduction of second generation anti-psychotics raised many hopes but several recent studies have nonetheless shown that their efficacy is comparable to some first-generation antipsychotics and they produce significant side effects ${ }^{2}$.

Unwanted side effects influence users' relationships with their bodies, feelings (lack of energy, feeling detached from one's emotions, loss of control over one's inner world, etc.), health (e.g., diabetes and weight gain), quality of life and chances of social reintegration ${ }^{3,4}$. For example, effects such as inability to concentrate and involuntary movements affect self-esteem, contribute to stigmatization and are obstacles to keeping a job or attending school.

The prescription of neuroleptics is a complex issue. Determining the correct medication and dosage to obtain a desired effect at the right time requires constant and attentive monitoring which, unfortunately, is not always performed. Studies have shown that some prescription practices are simply the result of limited access to other services in the system of care ${ }^{5}$. The long and painful processes that individuals go through in seeking help before succeeding in understanding and getting information on their diagnoses and treatments have also been observed ${ }^{6}$.

Qualitative research has gathered narratives in which users describe having symptoms such as a sense of dissociation from themselves and having trouble distinguishing between the effects of medication itself and difficulties arising from taking the medication ${ }^{7}$. Such difficulties are reinforced by a system of services that tends to obscure the limits of medication and its paradoxical effects on users.

In addition, many users attempt to abruptly stop taking their medication without support or monitoring ${ }^{2}$. Recent qualitative studies have led to a better understanding of why users decide to take their medication and highlighted the need to move beyond approaches centered on symptom control and compliance ${ }^{8-10}$.

\section{Beyond compliance: new perspectives}

A recent analysis of research into prescription practices supports the idea that optimal dosages change over the course of an illness and that pharmacological treatments must constantly be reassessed ${ }^{11}$. The authors conclude that the high dosages of neuroleptics produce greater side effects which subsequently are associated with a major risk of non-adherence to treatment, new crises and a negative effect on users' satisfaction with treatment ${ }^{12}$. They propose that prescribed dosages be systematically reduced as part of standard treatment protocols. The focus of interventions should be shifted away from the sole control of psychotic symptoms towards a more global and comprehensive approach.

Several recent models propose practices that provide significant room for dialogue and shared decision-making between the user and their prescribing physician ${ }^{13-15}$.

In all of these models there is a major shift in how pharmacological treatment, prescription practices, and the relationship between health care professionals and users are considered. It involves accepting people, and their suffering, and supporting them so that treatment is geared towards overall wellness and quality of life in the community.

It is in response to these numerous issues and difficulties posed by psychopharmacological treatment for individuals living with serious mental health problems, and at the initiative of some of these individuals, that the GAM approach emerged in the province of Quebec in the 1990s. The practices of GAM are based on the numerous experiences of users and were developed using a process of co-development and ongoing research by alternative and community mental health organizations in Québec, including advocacy groups. Through a partnership between the practice and research sectors, the approach was developed to take into account the many perspectives and relationships that users have with their medication, their knowledge and practices, their experience of mental health workers, and a thorough analysis of the current knowledge of psychotropic medications both in the field of biomedical research and in the human and social sciences. Today, GAM is recognized in Quebec as a "good practice» by the Health and Welfare Commissioner ${ }^{16}$.

This paper presents the principles, practices and primary impacts of GAM on how participants relate to their medication, and to their pre- 
scribing physicians, as documented by the research.

\section{Support practices and principles of GAM}

For users who take psychotropic medication, and for those seeking alternatives to ease emotional pain, the GAM approach offers a process by which users can reflect on their quality of life and on the roles that medication and other types of treatment play in their life trajectory and in their daily lives. GAM introduces support practices so that participants can identify the changes they need to make and then mobilize the available resources in order to ensure that their medication is contributing to their wellness. This process requires making room for dialogue between the participant directly affected, their loved ones, their peers, and the professionals they encounter (social workers, nurses, pharmacists, physicians, psychiatrists, etc.).

Workers and users from alternative community organizations have developed the various practices of the GAM approach. The main practices centre around the following aspects:

- Accessibility to information and education regarding medication, one's rights and the GAM approach.

- Opportunities for expression and discussion that allow users to share, with their peers, their experiences with medication and their relationships to mental health practices.

. Individual support in which one's relationship with medication and personal meanings are explored within a broader process geared towards change and improvement of quality of life. This structured process enables users to undertake a personal reflection on their quality of life, and to assess the role and effects of the medication they take. Users identify and mobilize resources based on the changes they want to make (e.g., get more information, facilitate communication with health care professionals, change a prescription). My GAM Guide is used to guide this process ${ }^{17}$.

. Support, preparation and guidance for meetings with the prescribing physician and other mental health workers in order to facilitate communication and negotiation.

These objectives may be achieved differently depending on the organization and resources available. The idea is to make various activities available and make use of different practices depending on the person's needs.

The practices of GAM are supported by five principles:
1. The importance of subjective quality of life

Quality of life, rather than adherence to treatment, is at the heart of the GAM approach. This priority guides the collaborative effort between professionals and medication users.

2. (Re) empowerment

GAM was born out of a deep desire, by medication users, to gain or regain control over their treatment. Indeed, the GAM approach requires that participants play an active role in their treatment and, more broadly, in their efforts towards wellness.

3. Recognition of medication's multiple meanings

GAM practices recognize the symbolic aspects of medication and require recognition of its multiple, and at times contradictory, meanings in the lives of users and various individuals involved in psychiatric treatment.

4. Respect for individuals, theirs decisions and rights

The fundamental values underlying the GAM approach are respect for people, their dignity, their freedom of choice and their rights, especially those involving free and enlightened consent to treatment. Health care workers provide support and guidance through a process in which participants make their own decisions, even if workers, family or friends, do not agree with them. It is an ongoing process to find shared solutions that both the individual seeking help and those striving to help can accept.

5. A broad approach to suffering and wellness

The GAM approach takes a non-reductionist view of mental health problems, highlighting the limitations of a single, one-dimensional, treatment and instead focusing on diverse aspects of suffering that are complex and multi-faceted in nature. It views the use of psychiatric medication to treat mental health problems as one tool, amongst many, that can support people in their progress and quest towards wellness.

\section{The effects of GAM \\ on participants' lives: outcomes}

Several studies were carried out in parallel with the development of the GAM approach ${ }^{6,18}$ which provided a better understanding of the complexity of users' relationships with psychiatric medication. This article presents partial results of one study aimed at documenting the different aspects of participants' experiences with the GAM process: 1 . the perceptions and practices of users with 
respect to psychiatric medication; 2 . their point of view on the GAM approach and its practices; 3. the limits and advantages of the GAM approach and its impact on participants' road to wellness.

\section{Deeper understanding}

\section{through qualitative analysis}

The analysis presented here is based on twenty-six interviews with people with serious mental health problems (psychotic symptoms, several psychiatric hospitalizations, usage of medication) carried out in two phases (Table 1): 1) sixteen interviews, performed in 2004, with individuals at eight community-based mental health organisations that had taken part in the GAM pilot project; 2) ten interviews, performed in 2010, with participants who had undertaken the GAM process in community-based mental health organisations that had systematically integrated the approach for the past ten years. In the first phase, two people per organization, that had taken part in GAM for at least one year, were selected by health care workers. Candidates were selected from amongst active GAM participants as well as from those who had a more distant or critical view of the approach. In the second phase, a sample was drawn randomly from a list of all participants who had undertaken the GAM process over the past five years.

Each participant took part in an individual, in-depth, semi-structured interview that covered their relationship with medication and the GAM process through the following six perspectives: 1 . Relationship with oneself: a) self-image, b) relation to symptoms and crises, c) interpretation of problems; 2. Relation to services and to public and community service workers: a) prescription conditions, b) follow-up conditions; 3. Perception of impacts on their relationships with others: a) perception of and attitude towards family and loved ones, b) perception of and attitudes towards other significant social groups identi- fied by the person; 4 . Life skills and quality of life; 5. Social integration and action, in terms of opportunities to: a) carry out personal projects and activities, b) take part in educational and volunteer activities, c) integrate socially and professionally; 6. Recovery and empowerment: a) description of and changes in problems and symptoms in life trajectory, b) description and evaluation of help-seeking strategies and of frequented mental health resources.

The analysis was carried out in two phases based on interview transcriptions. The researcher and two research assistants individually carried out an initial codification based on emerging themes. These were then compared and discussed, and a mutually agreed upon selection was made. A second interview codification was done based on these themes. All of the codified excerpts, along with interpretation notes, were compiled for more thorough analysis while remaining faithful to the interviewees' statements.

The research team used other data sources from previous research to validate the results: 1) participant observation reports at forty-five GAM training sessions; 3) fourteen semi structured interviews with managers, workers (public and community sectors), and parent groups.

\section{Results}

The interviewees spoke in depth about the space that pharmacological treatment occupied in their lives-how it changed their experiences and the conditions under which it became a tool that promoted wellness. We were struck by the richness of their accounts and reflections. This article describes the primary benefits of the GAM process, as highlighted by the interviewees, and its effect on their relationship with their medication and prescribers. We examine the benefits, limitations, and connections with various support practices.

Table 1. Evolution in medication consumption.

\begin{tabular}{lcc}
\hline Type of medication & $\begin{array}{c}\text { Number of users taking this type } \\
\text { of medication before GAM }\end{array}$ & $\begin{array}{c}\text { Number of users taking this } \\
\text { type of medication after GAM }\end{array}$ \\
\hline Neuroleptics & 17 & 13 \\
Antidepressants & 22 & 18 \\
Mood stabilizers & 6 & 5 \\
Anxiolytics (Anti-anxiety) & 20 & 17 \\
Insufficient data & 2 & $\mathbf{2 6}$ \\
Total number of participants & &
\end{tabular}


We use selected interview excerpts to illustrate the conclusions and analyses, since these reflect the kernels of common meaning in the interviewees' narratives, the issues they face, and the similar experiences encountered in their undertaking of the GAM approach. All the names of the interviewees have been changed in order to ensure confidentiality

\section{Knowing one's medication and rights}

In most cases, the GAM process raised participants' awareness of their right to make choices, their right to give free and informed consent, and the means of exercising those rights. For participants, knowledge of the medication was an essential aspect of GAM. Many participants already had strategies for finding information themselves but most participants' interest in this issue increased through their participation in the GAM process. This knowledge came from various sources: workers and peers, reference works (e.g., articles found at the resource organization, on the Internet, in guides on the effects of medications, the Compendium of Pharmaceuticals and Specialties, the GAM guide), workshops and training sessions (GAM and The Other Side of the Pill).

GAM is really knowing about your medication so you can deal with it... not saying 'take a blue pill and a red pill. No, no... it's knowing the side effects, the other effects ... noticing if you have problems, whether it be sleeping or other problems that arise ... so you can talk about them... -Diane

The GAM process cannot be reduced to access to technical information about medication (i.e., their positive effects or side effects). The information is used in a more comprehensive perspective that takes into account the way that people make sense of their experience of suffering, and of taking medication, and that aims to facilitate dialogue and cooperation with health care professionals, mental health workers, friends and family, and peers in a joint process of seeking the best ways to deal with problems and symptoms.

\section{Empowerment}

The GAM process therefore transformed participants' relationship with their medication, increased their sense of control, and allowed them to face their treatment and take their medication in a more active and more aware manner. Many referred directly to the notion of empowerment: "It means being able to make your own decisions, make your own choices, and have a vision of the thing other than just this little magic pill.... It gives you back power over your life. Once you realize you are able to make decisions you've taken a major step forward."

\section{Improving the relationship with health care professionals and making room for negotiation with the physician: preparing for meetings}

Participants in the GAM process transformed their relationship with health care professionals -particularly prescribing physicians - in a very positive way. The accounts relate a variety of collaborative experiences to find the best ways for medication to contribute to wellness.

More specifically, through the reflection, training, information, and discussion of experiences with peers, mental health workers and loved ones, afforded by GAM activities, participants were better equipped to express themselves to their doctors. They had more convincing arguments, were more nuanced in describing the effects of medication on their daily lives and progress, and were able to communicate their points of view and the expertise they had acquired in taking medication every day. This contributed to creating a constructive dialogue with the physician and facilitated his or her participation in the process of changing the medication or reducing the dosage.

For mental health workers, the research shows that physicians and other health care professionals are also reassured by the GAM approach because it assumes that the person using the medication is taking an active role, has embarked on a structured process supported by mental health professionals and a variety of resources, and understands that if it's necessary to change dosages, the process is very slow and controlled - as outlined in the GAM guide.

Gradually, a mutual recognition of their respective areas of knowledge develops, which creates room for negotiation and for making decisions that can be qualified as shared, even if the medication user's choices are given priority: "I have my expertise, my experience ... about medication and about mental health problems. And he also has an expertise about his knowledge of medication ... So we have to put the two together." 


\section{Changed attitudes towards medication: from the desire to stop taking them to increased control over experience and treatment}

\section{The desire and fears related to stopping medication}

In general, interviewees recalled that before taking part in the GAM process, they had resisted taking psychiatric medication and referred to numerous unsupported and sudden attempts to stop taking them. The reasons they gave primarily involved the medication's side effects. Overall, the analysis indicates that most interviewees took many different drugs simultaneously - drugs that had different and significant side effects.

The drug ... takes away some of your energy because you get so numb that ... any impulses you have are cut off, as if you're paralysed. ... Sometimes I had trouble leaving the house ... My main problem was with the medication, to agree to take it and keep taking it was tough. Maybe that's what caused so much in and out, all those years of relapsing. - Pierre

For others, despite the negative effects, medication was for a long time the only possible answer to great suffering: But I can say that yes, the medication helps me function at work. For sure, if I had not taken it, I don't know where I would have ended up. I'd probably be dead. - Colette

With the GAM approach, medication becomes just one tool amongst others to ease mental suffering. The sometimes obsessive desire to stop taking it is reduced, changed, or disappears for most people. In fact, the primary concern regarding GAM, amongst certain mental health workers, is access to information-especially the view that knowledge of the limitations of medication and their side effects will cause service users to abruptly stop taking their prescriptions. However, the observed effect is generally the opposite. Participants in the GAM process do not unilaterally stop taking their medication. If they decide that they need to reduce the number of medications they are taking, or their dosages, they develop a plan, in partnership with their doctor, and proceed thoughtfully and slowly, noting the changes in their mental and physical state, adjusting dosages, moving gradually back and forth in order to obtain prescriptions that fulfill their needs and that contribute to their wellness.

\section{Maintaining or changing prescriptions}

We noted that when given guidance and support, people tended to find a level of medication that suits them. The research shows that GAM encouraged people, in partnership with their physicians, to adjust their pharmacological treatment based on its contribution to improved quality of life and wellness. For some, this process involved a change in attitude and an acceptance of their treatment: I agreed to take medication, above all, because I saw the benefits of taking it. I was less rebellious ... I wrote things down in my notebook [GAM guide] about such and such a medication. ... It allowed me to accept and understand that I was in control of my life, even if I was on medication. That I was not a guinea pig. I deliberately decided to take them and I saw the benefit of it. That's what GAM allowed me to do. - Berthe

For others, changes in the drugs prescribed, the number of drugs they were taking, or the dosages (to reach a "comfortable dose") ... was the start of a new journey that has not ended. ... I have not finished working on myself but I could finally see a light at the end of the tunnel because I was taking back control over my life... My goal in coming here was to get off antidepressants completely. ... And she [the GAM counsellor] was always there when I needed her. ... She never judged me, it was always my choice. ... She took my living environment into account. ... That's the dose that was absolutely extraordinary for my self-esteem, my healing, my dignity, being able to take back control over my life, it made all the difference...to me ... to have ... options open to me, the return of the word 'healing'. - Jeanne

And finally, for a minority it meant a significant reduction or the complete cessation of psychotropic medication and the implementation of alternative strategies for dealing with the mental suffering and symptoms: I'm off medication, if need be. And I feel ready for it too, it's not just a refusal to take my medication. ... And I don't hesitate to take it when I need it. - Pierre

\section{Accepting to live}

\section{with a "degree of suffering"}

Most people arrive at a sort of compromise in order to reduce the dosage and number of medications they are taking. They often feel that they have to accept compromises, a "share of suffering": The medication doesn't solve everything. It helps you experience fewer symptoms but... There's a sort of share of suffering, where you tell yourself, 'I live with it, I'll continue to live with it'. - Anne

Because the drug completely paralyses me. At the same time, it takes away my symptoms, so I have a better quality of life. ... I have to deal with 
it, it's almost like you juggle with it ... with the different aspects to find a balance.... I have found a certain balance, but it's not perfect and ... it doesn't take away all [the suffering]. - Pierre

\section{Beyond medication: a}

\section{deeper understanding of the experience}

Beyond the issue of medication, the GAM approach offers a new perspective on the suffering that led people to seek psychiatric help. The GAM process helps people develop a greater selfknowledge by helping them name their emotions, identify the consequences of their lifestyle, and reflect on their relationships with others. This allows participants to find other forms of support and practices and to devise new strategies that broaden their ability to act in the face of suffering and crisis situations.

Right now, it's more important for me to work on the quality of my relationships with others, on the relationship I have with myself, to have a gentler relationship with myself. ... For me it's more important than reducing my medication. ... I think that gaining awareness is more important. ... [I] focus less on the medication. - Isabelle

\section{Reflections of wellness}

In all interviews with GAM participants, these changes were associated with the opening of new opportunities, with the ability to take on new projects and with a significant improvement in quality of life. Jeanne

I began to wake up in that way, gradually. -

Before, I was walking dead, alive but not inside. But now I'm alive. I'm 'not dead anymore.' My activities haven't changed, but I have much more hope about what I can do now. - Élise

I separated [from my partner], I stopped drinking, I stopped taking medication, I think it's part of an overall gaining of awareness that happened in small stages. GAM arrived just at the right time. - Diane

A light shone in the night. I was offered hope in a form other than pills. The hope of finally advancing towards who I am, of finding a natural balance, an inner movement rather than that immutable state, that shaky equilibrium artificially maintained by chemicals.... [The GAM approach] can be demanding, even painful at times. But for me it was a sort of necessary passage towards regaining my personal power, my dignity and my freedom to be and to act. - Julie

\section{Discussion}

The analysis presented in this article has identified several positive impacts of GAM practices, along with its limitations and significant challenges. First, it offers GAM participants the opportunity to gain autonomy with respect to their pharmacological treatment, to improve their quality of life and wellness, and to put alternative strategies into place for dealing with social and emotional suffering. Some of these strategies concern lifestyle and can be achieved by participants themselves (e.g., physical exercise, proper nutrition, stress management). Others involve significant social changes such as access to the socio-economic, community and cultural resources that allow people to realize their dreams and carry out personal projects, social participation through volunteer work, or the ability to negotiate working conditions or to make accommodations in order to succeed at school. Finally, access to settings where people can be heard and express personal experiences would appear to be essential to the process of making changes for most people. Hence, the place of pharmacological treatment with respect to other approaches in health services, and in society in general, should be questioned.

Despite the limitations and obstacles regarding their implementation, GAM and other approaches that seek to give a voice to people taking medication, and to make that voice an essential part of determining psychiatric treatment, are promising avenues, if not indispensable ones, in the future of community-based mental health practices.

By systematizing the knowledge acquired every day by medication users, GAM fosters the development of support practices that help put pharmacological treatment at the service of wellness.

In a similar vein, we have noted the recent emergence of several promising models that share with GAM the same observations of the limitations of approaches based on the monitoring of prescriptions and their promotion of adherence. These models aim to fundamentally transform the relationship between professionals and patients. Among the more well-known of these are the "shared decision" approach ${ }^{13,15,19}$ which was the topic of a Cochrane study in $2010^{14}$ and the "harm reduction" approach ${ }^{20,21}$. The GAM approach shares several objectives for transforming practices with these models:

- recognition of users' knowledge

. making available information on medications' effects 
- broadening users' ability to decide, choose and act more autonomously regarding medication

- changing users' relationships with health care professionals, particularly prescribing physicians

This is a major paradigm shift in the concept of the relationship between health care professionals and patients, one that seeks autonomy and recovery through a recognition of the knowledge that users have gained through their experience of daily consumption of medication. This creates a new field for the development of innovative practices-one that deserves study.

In this context, certain distinguishing features of GAM's contribution can be identified. It involves not only the recognition, and dialogue between various kinds of knowledge (such as users' and professionals' experiences and research), but a sharing of the uncertainty surrounding the limits of pharmacological treatments and the multidimensional and complex nature of mental health issues. As such, GAM questions the dominant place of pharmacological treatment and the quest for certainties upon which it is based. This poses a considerable challenge for health care professionals, for medication users, and for their loved ones-challenges that can only be overcome by working together to find solutions that take users into account.

GAM revolves around the multiple experiences of people taking medication, their desires with respect to identifying the changes they wish to make, and their concept of quality of life in the community. More specifically, it provides users with the opportunity to embark on a thorough contemplation of the symbolic aspects of medication (both stated and implied), a contemplation of themselves, of their inner world and emotions, of their symptoms, of their lifestyle and of their social network. GAM relies on the mobilization of health care services but also on existing community resources. It seeks to develop flexible and creative support practices, based on respect for rights, paving the way for the full exercise of citizenship enabling users to fully participate in society.

\section{Collaborations}

L Rodriguez del Barrio, C Cyr, L Benisty and P Richard participated equally in all stages of preparation of the article. 


\section{References}

1. Fowler D, Garety P, Kuipers E. Therapie cognitive behaviorale des psychoses. Santé mentale au Québec 1999; 24(1):61-88.

2. Liberman JA, Stroup TS, McEvoy JP, Swartz MS, Rosenheck RA, Perkins DO, Keefe RS, Davis SM, Davis CE, Lebowitz BD, Severe J, Hsiao JK; Clinical Antipsychotic Trials of Intervention Effectiveness (CATIE) Investigators. Clinical antipsychotic trials of intervention effectiveness investigators: Effectiveness of antipsychotic drugs in patients with schizophrenia. N Engl J Med 2005; 353(12):1209-1223.

3. Corrigan PW, Reinke RR, Landsberger SA, Charata A, Toombs GA. The Effects of Atypical Antipsychotic Medications on Psychosocial Outcomes. Schizophr Res 2003; 63(2):97-101.

4. Weiden PJ, Dixon L, Frances A, Appelbaum P, Haas G, Rapkin B. Neuroleptic Noncompliance in Schizophrenia. In: Tamminga CA, Schulz SC, editors. Advances in Neuropsychiatry and Psychopharmacology. Schizophrenia Research. New York: Raven Press; 1991. p. 285-296.

5. Commission de l'éthique, de la science et de la technologie (CEST). Médicaments psychotropes et usages élargis: un regard éthique. Québec: CEST; 2009.

6. Rodriguez L, Corin E, Poirel M-L. Le point de vue des utilisateurs sur l'emploi de la médication en psychiatrie: une voix ignorée. Revue québécoise de psychologie 2001; 22(2):201-223.

7. Rodriguez L, Corin E, Guay L. La thérapie alternative: se (re)mettre en mouvement. In Lecompte Y, Gagné J. Les ressources alternatives de traitement. Québec: Santé Mentale au Québec, RRASMQ; 2000. p. 49-94.

8. Roe D, Goldblatt H, Baloush-Klienman V, Swarbrick M, Davidson L. Why and how people decide to stop taking prescribed psychiatric medication: Exploring the subjective process of choice. Psychiatr Rehabil J 2009; 33(1):38-46.

9. Britten N, Riley R, Morgan M. Resisting psychotropic medicines: a synthesis of qualitative studies of medicine-taking. Advances in psychiatric treatment 2010; 16:207-218.

10. Rogers A, Day JC, Williams B, Randall F, Wood P, Healy D, Bentall RP. The meaning and management of neuroleptic medication: a study of patients with a diagnosis of schizophrenia. Soc Sci Med 1998; 47(9):1313-1323.

11. Yamin S, Vaddadi K. Are we using excessive neuroleptics? An argument for systematic neuroleptic dose reduction in stable patients with schizophrenia with specific reference to clozapine. Int Rev Psychiatry 2010; 22(2):138-147.
12. Hofer A, Kemmler G, Eder U, Honeder M, Hummer M, Fleischhacker W. Attitudes towards antipsychotics among outpatient clinic attendees with schizophrenia. J Clin Psychiatry 2002; 63(1):49-53

13. Drake RE, Deegan PE, Rapp C. The Promise of Shared Decision Making in Mental Health. Psychiatr Rehabil J 2010; 34(1):7-13.

14. Duncan E, Best C, Hagen S. Shared decision making interventions for people with mental health conditions. Cochrane Database Syst Rev 2010; (1): CD007297.

15. Matthias MS, Salyers MP, Rollins AL, Frankel RM. Decision Making in Recovery-Oriented Mental Health Care. Psychiatr Rehabil J 2012; 35(4):305-314.

16. Health and Welfare Commissioner. Appraisal Report of the Performance of the Health and Social Services System. Quebec: Health and Welfare Commissioner; 2012.

17. Regroupement des ressources alternatives en santé mentale du Québec, Association des groupes d'intervention en défense des droits en santé mentale du Québec. Taking Back Control; My Self-management Guide to Psychiatric Medication. Québec: Regroupement des ressources alternativesen santé mentale du Québec; 2003.

18. Rodriguez L, Perron N, Ouellette JN. Psychotropes: réguler ou écouter la souffrance. In: Blais L, editeur. Vivre à la marge: réflexions autour de la souffrance sociale. Québec: Les Presses de l'Université Laval; 2008. p. 121-148.

19. Deegan PE, Drake RE. Shared decision making and medication management in the recovery process. Psychiatr Serv 2006; 57(11):1636-1639.

20. Aldridge MA. Addressing non-adherence to antipsychotic medication: a harm-reduction approach. J Psychiatr Ment Health Nurs 2012; 19(1):85-96.

21. Hall W. Harm Reduction Guide to Coming Off Psychiatric Drugs. $2^{\text {nd }}$ Edition. New York: Icarus Project, Freedom Center; 2012.

Artigo apresentado em 29/04/2013

Aprovado em 19/05/2013

Versão final apresentada em 06/06/2013 